\title{
Observação do VTEC durante uma tempestade geomagnética na região equatorial da Amazônia Central com auxílio de GPS e da Transformada em Ondeleta de Morlet, na camada $F$ ionosférica.
}

\author{
${ }^{1}$ LIMA, N., ${ }^{1}$ FERREIRA, A., ${ }^{1}$ SILVA, R*., ${ }^{1}$ GÓES, K., ${ }^{1}$ FARIAS, T. \\ (1) Centro Universitário Luterano de Manaus - CEULM/ULBRA \\ Av. Carlos Drummond de Andrade, 1460. Conjunto Atílio Andreazza. Bairro Japiim II. \\ Manaus-AM/Brasil. CEP. 69077-730. Tel. (92) 3616-9800. \\ (e-mail:newtonulbra@gmail.com)
}

\begin{abstract}
Copyright 2016, SBGf - Sociedade Brasileira de Geofísica
Este texto foi preparado para a apresentação no VII Simpósio Brasileiro de Geofísica, Ouro Preto, 25 a 27 de outubro de 2016. Seu conteúdo foi revisado pelo Comitê Técnico do VII SimBGf, mas não necessariamente representa a opinião da SBGf ou de seus associados. É proibida a reprodução total ou parcial deste material para propósitos comerciais sem prévia autorização da SBGf.
\end{abstract}

\section{Resumo}

Este artigo traz informações do comportamento do plasma ionosférico da camada $\mathrm{F}$ da região equatorial da Amazônia brasileira, durante uma Dst (17-18 Março 2015), utilizando um GPS ionosférico de dupla frequência, com análise de TEC comparado a Transformada em Ondeleta de Morlet. As observações mostraram que a técnica de aquisição do VTEC é satisfatória para identificação do fenômeno indicado.

\section{Introdução}

Observações sobre o comportamento do plasma ionosférico na camada $\mathrm{F}$ é importante para compreensão do clima espacial (Sahai, et al., 2009). Em março de 2015, o Sol encontrava-se em período de atividade máxima dentro do ciclo solar \# 24 para o fluxo de rádio de comprimento de onda $10,7 \mathrm{~cm}$. O fluxo de rádio solar em 10,7 centímetros $(2800 \mathrm{MHz})$ muito valioso na especificação e previsão do clima espacial é um excelente indicador da atividade solar. As emissões de ondas de rádio no comprimento de onda de $10,7 \mathrm{~cm}$ originam-se na zona de transição entre cromosfera e coroa (SILVA, 2006; SWPC-NOAA, 2015), da atmosfera solar. O F10.7 correlaciona-se bem com o número de manchas solares, bem como a emissão de ultravioleta (UV) e da irradiação solar visível cujas as emissões podem afetar a ionosfera e modificar a atmosfera superior. Sendo quantificado em "unidade de fluxo solar", (SFU), o F10.7 pode variar de $50 \mathrm{sfu}-300 \mathrm{sfu}$, ao longo de um ciclo solar. Em Março de 2015, ocorreu variação de 120 sfu a 160 sfu, (SWPC-NOAA, 2015).

\section{Metodologia}

Este trabalho teve como base o monitoramento do VTEC, na região equatorial, e as irregularidades ionosféricas de grande escala (Bolha de Plasma), também de pequena escala (cintilações), tempestades geomagnéticas e Distúrbios lonosféricos Viajantes (TID em inglês) (LIMA, 2010). Com as medidas de VTEC, realizadas na Estação de Manaus (Fig. 01), estes fenômenos são caracterizados através de construção de gráficos e posteriormente comparados com os índices geomagnéticos através da série temporal de Dst do mês de Março de 2015 e com a Transformada em Ondeleta de Morlet, que veremos a seguir (PIETZSCH, et al., 2013). O erro associado por cintilação $\left(S_{4}\right)$ do sinal GNSS (Global NavigationSatellite System) é mais comum à noite dependendo do tipo do canal receptor, as cintilações (irregularidade de pequena escala) podem causar um aumento nas perdas de ciclos (cycleslips) e até mesmo a impossibilidade de realizar medições. A quantidade de elétrons ao longo do comprimento do percurso é referida como contagem total de elétrons (1) e é definido pela expressão:

$$
T E C=\int n_{e} d l
$$

O TEC é expresso em unidades de elétrons $/ \mathrm{m}^{2}$ ou ocasionalmente nas unidades do TEC (TECU), para $\boldsymbol{n}_{e}$ número de elétrons livres, sendo $1 \mathrm{TEC}=10^{16}$ elétrons livres $/ \mathrm{m}^{2}$.

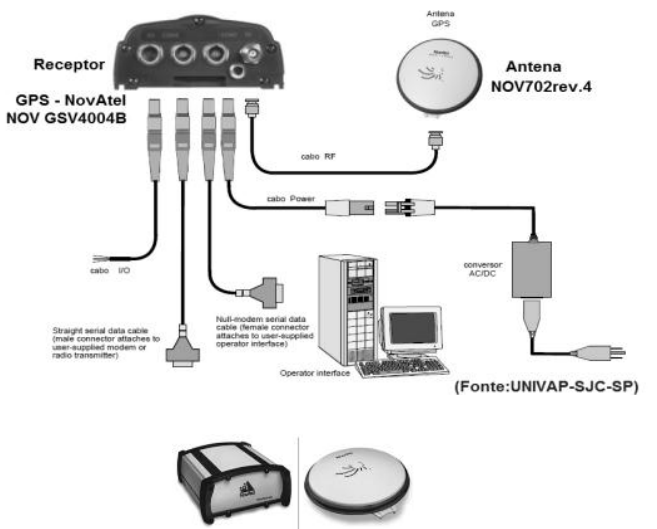

Fig. 01. Diagrama pictórico da configuração do equipamento na Estação em Manaus; Receptor e antena (GPS - NovAtel - NOV GSV4004B - Antena NOV702 rev.4). 


\section{A Transformada em Ondeleta (TO)}

O termo ondeleta, também conhecido por "wavelet" refere-se a um conjunto de funções com forma de pequenas ondas geradas por dilatações, $\psi(\mathrm{t}) \rightarrow \psi(2 \mathrm{t})$, e translações, $\psi(\mathrm{t}) \rightarrow \psi(\mathrm{t}+1)$, de uma função geradora simples $\psi(\mathrm{t})$, a ondeleta-mãe. Esta deve ser quadraticamente integrável dentro de um intervalo de tempo real ou espaço $\left[\mathrm{L}^{2}(\Re)\right]$, isto é, deve apresentar energia finita. A imposição de que a sua energia média seja zero, constitui a condição de admissibilidade da função.

\section{Resultados e Discussão}

O monitoramento do VTEC pelo Laboratório da lonosfera (Estação MAN) entrou em pane (blackout) na aquisição de dados da rede de satélites GPS (Global Satellite System) entre os dias 17 a 26 de Março de 2015, decorrente de uma tempestade geomagnética Dst de índice considerado severo de -228 nT. Estes índices tem os seguintes critérios: até - $30 n T$, considerado baixo; até - $60 \mathrm{nT}$, considerado médio e até - $100 \mathrm{nT}$, forte.

No dia 17 de Marçode 2015, houve forte tempestade geomagnética com comprome-timento de toda rede de satélite ao redor da Terra (Fig. 02). A advertência ao fenômeno de tempestade geomagnética pelos cientistas é decorrente da tecnologia existente na Terra ocorrer alteração de surtos no funcionamento dos equipamentos por efeito de indução eletromagnética; principalmente alteração do clima espacial monitorados pela rede de satélites artificiais GPS (LISN) como degradação do sinal nos perfis de VTEC indicando instabilidade do plasma ionosférico da camada F previsto por Sahai $(2000,2005$ e 2009), além de alerta na Estação Espacial Internacional em operação de Atividade Extraveicular $(E V A)$ e das linhas de transmissões de eletricidade e telecomunicações (Rádio Comunicação) nos hemisférios Norte e Sul do Globo Terrestre (SWPC-NOAA, 2015).

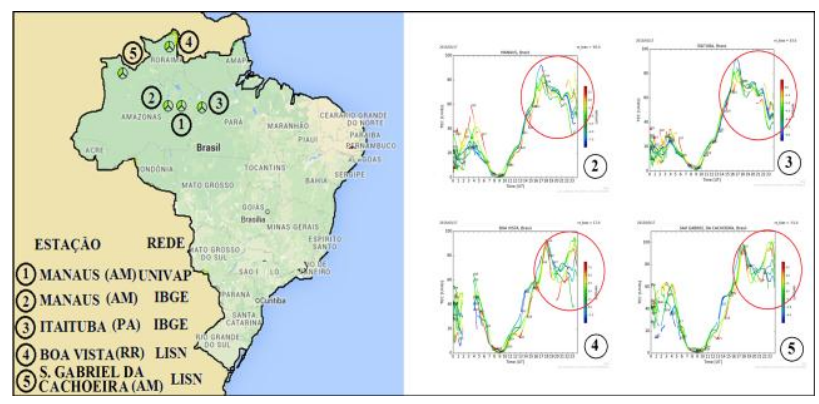

Fig. 02: Mapa indicando posicionamento de sensores GPS na Amazônia brasileira que mostraram no dia 17 de Março de 2015, Distúrbio lonosférico Viajante (TID Travelling lonospheric Disturbance) com degradação do sinal GPSem destaques nas estações citadas.

Porém, nem toda vez que há explosão no Sol a massa coronal atinge a Terra; vai depender se o nosso planeta está na rota de colisão. Também, se vai haver tempestade geomagnética ou não; vai depender se a informação magnética seja de natureza atrativa ao campo da magnetosfera terrestre. Esta tempestade geomagnética supracitada foi captada pelo equipamento da Estação MAN (Manaus - Brasil), (-3,1; -59,9).

Observa-se na Fig. 03, o desenvolvimento da tempestade geomagnética do dia 17 de Março de 2015, durante as noites que antecederam a tempestade e inclusive no dia houve formação de bolhas de plasma sobre o alvo, no dia 17 de Março de 2015 das 16 h (UT) até as 24 h (UT) (Fig.03), o plasma ionosférico encontra-se bastante excitado com forte degradação do sinal GPS, a partir deste dia a estação entra em pane realizando aquisição de dados para os arquivos numéricos incompletos ou simplesmente não adquirindo, este comportamento vai se normalizar no dia 26 de Março de 2015, mas foi somente neste dia e volta a entrar em falha operacional (veja Fig. (03) extrema direita). A série temporal criada a partir de dados de magnetrômetros da "World Data Center", torna possível entender de quanto a magnetosfera terrestre foi afetada neste dia, a transformada em Ondeleta de Morlet traduz três parâmetros importantes deste fenômeno geofísico; o primeiro parâmetro mostra o desenvolvimento da tempestade geomagnética, que entre os períodos de 0,5 até 8 dias (eixo das ordenadas) o evento é descrito com $95 \%$ de confiabilidade, visto que, encontra-se dentro do cone de confiabilidade; segundo parâmetro, indica o tempo (eixo das abscissas) de duração do fenômeno que estende-se por mais de 12 dias; e finalmente no terceiro parâmetro, trás a intensidade do sinal geofísico que ganha destaque exatamente no dia 17 de Março de 2015, quando mostra o contorno do espectro de cor no gráfico registrando a assinatura da $D$ st, característica principal de ênfase no critério dentro do gráfico da Fig. 03.

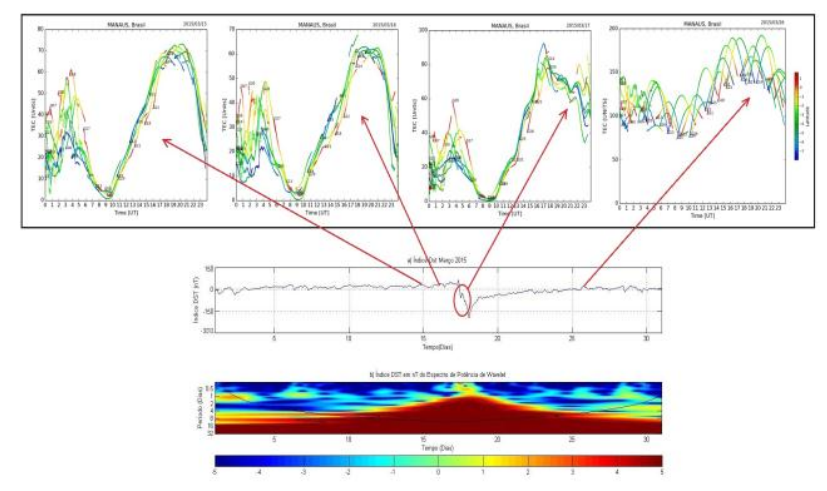

Fig. 03: Painel de VTEC, Dst em Série Temporal e Transformada em Ondeleta de Morlet para o mês de Março de 2015, com ênfase aos dias do entorno da Dst observada em Manaus (Amazônia Central).

\section{Conclusões}

A comprovação da instabilidade do plasma ionosférico degradando a aquisição do sinal no sistema GNSS nos horários do evento da Dst (17 de Março de 2015) ficou 
esclarecida, quando os GPS ficaram com aquisição comprometida em todas as estações.

Logo, com auxílio de VTEC obtido por GPS é possível identificar Dst na latitude equatorial na Amazônia Central.

\section{Agradecimentos}

Os autores são imensamente gratos pelo suporte do Edital 030/2013 UNIVERSAL FAPEAM; A Low-Latitude lonospheric Sensor Network (LISN), pelos dados de VTEC das estações de Boa Vista (LISN-RR/BR); Itaituba (IBGE-PA/BR); Manaus (IBGE-AM/BR); São Gabriel da Cachoeira (LISN-AM/BR). Ao Dr. Maurício Bolzan, (UFGJataí) sobre a utilização da Transformada em Ondeleta de Morlet e também a Christopher Torrence e Gilbert P. Compo pela rotina da Transformada. (Através do endereço internet, abaixo).

(http://atoc.colorado.edu/research/wavelets).

\section{Referências}

LIMA, N., ARAÚJO, R., FERREIRA, A. (2010).Observations of MSTIDs/GWs at the F2 layer heights in the near equatorial region.Section: SPAAeronomy (SA); Session SA08. AGU- 08-12 AUG 2010 /Foz do Iguassu-Brazil. The Meeting oftheAmericas.

PIETZSCH, M., LIMA, N., MEAZZA, K., FERREIRA, A, NOMURA, I. and BARBOSA, K. (2013). Observations of TEC and Dst values using wavelet transform in F2 layer near the equatorial region in August 2011. 13 th. Congress International of the Brazilian Geophysical Society \& EXPOGEF - Rio de Janeiro-Brazil (Aug. 2013) Session: SO-07. Engineering \& Environmental Geophysics.

SAHAI, Y, BECKER-GUEDES, F., FAGUNDES, P. R., DE JESUS, R., DE ABREU, A. J., OTSUKA, Y., SHIOKAWA, K., IGARASHI, K., HUANG, C. -S., LAN, H. T., SAITO, A., FERREIRA, A. S., LIMA, N. S., GAURNIER, F. L., VIEIRA, L. E. A., PILLAT, V. G., BITTENCOURT, J. A. 2009. Effects observed in the Fregion in two well-separated longitudinal sectors during the intense geomagnetic disturbances in the early part of November 2004. JOURNAL OF GEOPHYSICAL RESEARCH, VOL. 114, A00A19, doi:10.1029/2007JA013007.

SAHAI, Y., P. R. FAGUNDES, and J. A. BITTENCOURT (2000), Transequatorial $F$ region ionospheric plasma bubbles: Solar cycle effects, J. Atmos.Sol. Terr. Phys., 62, 1377-1383, doi:10.1016/S1364-6826(00)00179-6.

SAHAI, Y., P. R. FAGUNDES, F. BECKER-GUEDES, J. R. ABALDE, G. CROWLEY, X. PI, K. IGARASHI, G. M. AMARANTE, A. A. PIMENTA, and J. A. BITTENCOURT (2004), Longitudinal differences observed in the ionospheric $\mathrm{F}$ region during the major geomagnetic storm of 31 March 2001, Ann. Geophys., 22, 3221- 3229.

SILVA, A. V. R.2006. Nossa estrela: O Sol, Sociedade Brasileira de Física, Ed. Liv. da Física, São Paulo. 168 p.

SWPC-NOAA (2015): Space Weather Prediction Center/National Oceanic and Atmospheric Administration, in http://www.swpc.noaa.gov/ (access in 2015, March). 